\title{
Effects of Routine Antithrombotic-Adjusted Dose of Rivaroxaban and Nadroparin Calcium on Tendon Healing of Rats: An Experimental Study
}

\author{
Suleyman Altun ${ }^{1}$ Mehmet Sukru Sahin ${ }^{2}$ Gokhan Çakmak ${ }^{2}$ Kemal Gokkus ${ }^{20}$ Aysen Terzi ${ }^{1}$ \\ ${ }^{1}$ Department of Orthopaedics and Traumatology, Baskent University \\ Faculty of Medicine, Baskent University Hospital, Çankaya/Ankara, Turkey \\ 2 Department of Orthopaedics and Traumatology, Baskent University \\ Alanya Research and Practice Center, Alanya/Antalya, Turkey \\ Address for correspondence Kemal Gokkus, MD, Department of \\ Orthopaedics and Traumatology, Baskent University Alanya Research \\ and Practice Center, Saray Mahallesi Yunus Emre Caddesi No: 1, 07400 \\ Alanya/Antalya, Turkey (e-mail: kgokkus@gmail.com).
}

J Hand Microsurg 2023;15:133-140.

\section{Abstract \\ Keywords \\ - rivaroxaban \\ - nadroparin calcium \\ - Achilles tendon rupture \\ - Achilles tendon healing}

Introduction Achilles tendon injury necessitates thromboembolism prophylaxis after repair. This study aimed to investigate the effects of antithrombotic-adjusted prophylactic doses of nadroparin calcium and rivaroxaban on Achilles tendon healing.

Materials and Methods Twenty-four young adult male Wistar Albino type rats were randomly divided into three groups. All rats underwent a full-thickness surgical incision of the Achilles tendon, followed by primary repair. After the procedure, group 1 was determined as the control group and received no medication. Group 2 received $2.03 \mathrm{mg} / \mathrm{kg}$ rivaroxaban daily via gastric lavage once daily, and group 3 was given subcutaneous 114 IU AXa nadroparin calcium once daily for 28 days. After euthanization, the degrees of inflammation, neovascularization, fibroblastic activity, and collagen fiber sequencing were examined and scored for histopathological evaluation. The Statistical Package for Social Science (SPSS) version 21.0 for Windows software (SPSS, Inc., Chicago, Illinois, United States) was used for all statistical analyses. The number of inflammatory cells, capillary vessels, and fibroblasts, which met the parametric tests' assumptions, were compared between three independent groups by one-way analysis of variance. The significance level was set at $p$-value $<0.05$.

Results Histological examination of the group 1 sample showed the presence of inflammatory cells, an increase in the number of fibroblasts, and sequencing of collagen fibers scattered. The presence of inflammatory cells, remarkable increases in the number of fibroblasts, the presence of mature collagen fibers, and regular sequencing of collagen fibers regular were shown in groups 2 and 3. There were statistically significant differences between the groups regarding the number of inflammatory cells and fibroblasts. In group 2, the number of inflammatory cells was lower than in groups 1 and 3 . Elsewhere, the number of fibroblasts was higher in group 1 compared than in groups 2 and 3.

Conclusion Both rivaroxaban and nadroparin calcium in their daily dosage have a beneficial effect on Achilles tendon healing. article published online June 29, 2021
DOI https://doi.org/ $10.1055 / \mathrm{s}-0041-1729468$. ISSN 0974-3227. (c) 2021. The Author(s).

This is an open access article published by Thieme under the terms of the Creative Commons Attribution-NonDerivative-NonCommercial-License, permitting copying and reproduction so long as the original work is given appropriate credit. Contents may not be used for commercial purposes, or adapted, remixed, transformed or built upon. (https://creativecommons.org/ licenses/by-nc-nd/4.0/).

Thieme Medical and Scientific Publishers Pvt. Ltd. A-12, 2nd Floor, Sector 2, Noida-201301 UP, India 


\section{Introduction}

Despite important developments in biological and biomechanical treatment modalities, tendon healing remains a major orthopaedic challenge. ${ }^{1}$ Achilles tendon rupture is one of the most common ruptures with an increasing incidence and which often results in fibrotic scar tissue formation that has poor tissue quality and inferior mechanical properties. ${ }^{2,3}$ It has been reported that Achilles tendon injuries either fail to heal or demonstrate a delay in healing due to complications, such as prolonged postoperative recovery time, deep vein thrombosis, skin necrosis as well as infection around the surgical site and rerupture. $^{4-6}$ Several studies on Achilles tendon healing have investigated the efficiency of both conservative and operative care, with each management strategy offering unique risks and benefits. ${ }^{7-9}$ The effects of stem cells, ${ }^{10}$ and growth factors ${ }^{11}$ platelet-rich plasma ${ }^{12,13}$ on tendon healing, have been thoroughly studied over the past decades. However, there remains insufficient evidence regarding which strategy is the most effective.

Venous thromboembolism is a severe condition that can occur as a result of musculoskeletal system trauma and is a common source of postoperative morbidity and mortality, lest appropriate steps are taken..$^{14}$ As with other orthopaedic injuries, Achilles tendon injury necessitates thromboembolism prophylaxis after repair, or conservative treatment with long leg-cast immobilization. ${ }^{14}$

We believe that it is crucial to understand the effect of thromboembolism prophylaxis on tendon healing, but there are a limited number of studies regarding the impact of enoxaparin and rivaroxaban, which are widely used in thromboembolism prophylaxis on tendon healing. ${ }^{15-17}$ Among these, one study investigated the effect of rivaroxaban on tendon healing with an unadjusted dosage of 3 $\mathrm{mg} / \mathrm{kg}$, whereas another focused on the effects of two varying doses of nadroparin calcium on tendon healing: one dose was very close to $0.4 \mathrm{~mL} /$ daily with the other being $0.8 \mathrm{~mL} /$ daily. However, there are no studies investigating the effect of rivaroxaban's (with an adjusted dose) on tendon healing as a novel oral agent. This study aimed to investigate the effects of antithrombotic prophylactic doses (adjusted doses) of nadroparin calcium and rivaroxaban on Achilles tendon healing in a histopathological manner.

\section{Materials and Methods}

The present study was conducted at the Experimental Animal Breeding and Research Center of Baskent University. The study was conducted between August 2013 and October 2013, following the Declaration of Helsinki principles. This study's ethical approval was obtained from the Ethics Committee for Animal Experiments of Baskent University (approval number: DA13/36).

\section{Experimental Design}

Twenty-four young adult male Wistar Albino type rats of the same age, weighing $350 \pm 50 \mathrm{~g}$, were randomly divided into three groups. All animals were housed in an environment with 12-hour light and 12-hour dark cycles, 55\% humidity, and $21 \pm$ $2^{\circ} \mathrm{C}$; they were fed with standard feed. All rats underwent a full-thickness surgical incision of the Achilles tendon, followed by primary repair (SA). After the procedure of the Achilles tendon, group 1 was determined as the control group and received no medication. Group 2 received $2.03 \mathrm{mg} / \mathrm{kg}$ rivaroxaban equal to $0.6 \mathrm{mg}$ rivaroxaban/daily (Xarelto, Bayer HealthCare, Berlin, Germany) via gastric lavage once daily, for 28 days. The adjusted dose of rivaroxaban for rats was calculated according to the study of Nair and Jacob. ${ }^{18,19}$

Group 3 was given subcutaneous 114 IU AXa nadroparin calcium (Fraxiparine, Glaxo SmithKline, Canada) as lowmolecular-weight heparin (LMWH), once daily for 28 days. The adjusted dose of nadroparin calcium for the rats was calculated according to the study of Nair and Jacob. ${ }^{18,19}$ The rats were given free access to food and water as well as free movement within their cages and the guidelines for the care and use of laboratory animals in biomedical research were closely followed. ${ }^{20}$

\section{Surgical Procedure}

Before the surgery, $6 \mathrm{mg} / \mathrm{kg}$ xylazine and $70 \mathrm{mg} / \mathrm{kg}$ ketaminehydrochloride were administered for anesthesia by a researcher without clinical involvement. The right lower extremities of the rats were wiped with povidone-iodine (Adeka İlaç ve Kimyasal Ürünler San. Ve Tic. A.Ş) and shaved. An approximately- $1.25 \mathrm{~cm}$ longitudinal incision was performed under sterile conditions on the right Achilles tendon. The tendon was exposed and cut transversely from approximately $0.5 \mathrm{~cm}$ proximal to the side of the right Achilles tendon insertion site via the scalpel blade (no.10). The incised right Achilles tendon was then repaired with the Kessler method using polydioxanone 4-0 (PDS II Ethicon Inc., Sommerville, United States), and the skin was sutured using 3-0 polyglactin 910 (Coated Vicryl - Ethicon Inc., Sommerville, United States) (- Fig. 1).

One week after the surgery, infection protection was applied twice a day by intraperitoneal administration of $30 \mathrm{mg} / \mathrm{kg}$ cefazolin sodium (Iespor), and postoperative pain management was performed by subcutaneous administration of $0.02 \mathrm{mg} / \mathrm{kg}$ fentanyl. Neither postoperative immobilization nor postoperative exercise training was carried, and the wounds were sterilely dressed for 5 days. The decision against the immobilization was based on studies Murrell et al and Eliason et al. They reported that immobilization effects negatively affected healing after Achilles tendon repair in a rat model. ${ }^{21,22}$

On the postoperative 29th day, euthanasia was performed through high-dose anesthesia with $100 \mathrm{mg} / \mathrm{kg}$ thiopental sodium.

\section{Histological Analysis}

After euthanization, all Achilles tendons were resected proximal and distal ends of the adhesion site via the scalpel blade (no.10) and sent for histopathological examination. The Achilles tendon samples were fixed in 10\% formaldehyde. The specimens were embedded in paraffin, and sections of $5 \mathrm{~mm}$ thickness were prepared on slides. After deparaffinization, the sections were stained with hematoxylin and 

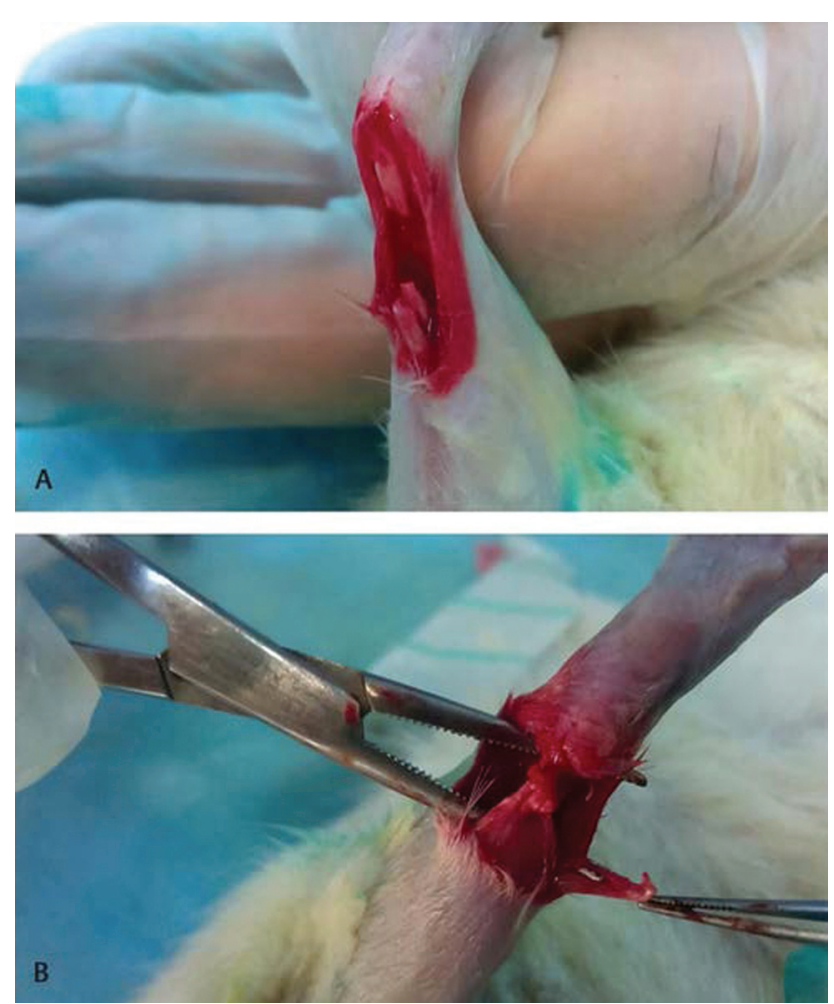

Fig. 1 Calcaneus and gastrocnemius tips of Achilles tendon after partial tenotomy $(A)$; primary repair of calcaneus and gastrocnemius tips of Achilles tendon after partial tenotomy (B).

eosin. The degrees of inflammation, neovascularization, fibroblastic activity, and collagen fiber sequencing were examined and scored for histopathological evaluation under a light microscope at 400 magnification. The healing condition of the tendons was measured histopathologically by using Curtis and Delee's staging method. ${ }^{23}$

The degree of inflammation and fibroblastic activity was rated as follows: none (0), mild (1), moderate (2), and pronounced (3). Neovascularization was rated based on the number of capillaries per high-powered field in a 0.45 micron diameter magnification area. Less than five was rated as mild (1), 5 to 10 rated as moderate (2), and greater than ten rated as pronounced (3). Collagen fiber sequencing was rated as follows: scattered (1), slightly regular (2), and regular (3).

Healing tissue samples $(5 \mathrm{~mm}$ diameter full-thickness biopsies from the Achilles tendon) were also obtained for histologic evaluation. The number of inflammatory cells (excluding histiocytes), capillary vessels, and fibroblasts were counted in three randomly selected large $10 \times$ magnification areas and were averaged. In each magnification area, counts were performed within a total area of $0.0625 \mathrm{~mm}^{2}$, divided into 100 square areas. All histopathological analyses were performed by a pathologist who was blinded to the study groups.

\section{Statistical Analysis}

The Statistical Package for Social Science (SPSS) version 21.0 for Windows software (SPSS, Inc., Chicago, Illinois, United States) was used for all statistical analyses. Data are shown as the mean \pm standard deviation, median, minimum, and maximum values, and interquartile range. Before statistical analysis, the Shapiro-Wilk test was used to assess the distribution of the data. Levene's test analyzed homogeneity of variances and the Kruskal-Wallis $\mathrm{H}$ test with a post hoc Dunn test was used to determine whether there was a significant difference in the degree of inflammation, neovascularization, fibroblastic activity, and collagen fiber sequencing between groups. The number of inflammatory cells, capillary vessels, and fibroblasts, which met the parametric tests' assumptions, were compared between three independent groups by one-way analysis of variance and Tukey's honestly significant difference) test was used for multiple comparisons. The significance level was set at $p$-value $<0.05$.

\section{Results}

There were no perioperative complications during the surgical procedure. Following rivaroxaban and nadroparin calcium administration, no early or late complications were observed during the study, including systemic or local side effects. The degree of inflammation, neovascularization, fibroblastic activity, and collagen fiber sequencing is shown in -Table 1. There was a statistically significant difference in the degree of inflammation and collagen fiber sequencing among the groups. The degree of inflammation was higher in group 1 compared than in groups 2 and $3(p=0.02$ and $p=0.02$, respectively). Otherwise, the score of collagen fiber sequencing was lower in group 1 compared than in groups 2 and 3 ( $p=0.04$ and $p=0.001$, respectively) ( - Table 1 ).

Histological examination of the group 1 sample showed the presence of inflammatory cells, an increase in the number of fibroblasts, and sequencing of collagen fibers scattered (-Fig. 2A). The presence of inflammatory cells, remarkable increases in the number of fibroblasts, the presence of mature collagen fibers, and regular sequencing of collagen fibers were shown in groups 2 and 3 (-Figs. 2B and $\mathbf{C}$ ).

The findings obtained in accordance with the histological analysis are summarized in -Table 2 ). There was no significant difference in the capillary vessels among the groups $(p=0.11)$. Conversely, there were statistically significant differences between the groups regarding the number of inflammatory cells and fibroblasts $(p=0.01$ and $p=0.002$, respectively). In group 2 , the number of inflammatory cells was lower than groups 1 and $3(p=0.01$ and $p=0.01$, respectively). Elsewhere, the number of fibroblasts was higher in group 1 compared than in groups 2 and 3 $(p=0.01$ and $p=0.003$, respectively) (-Table 2 ).

\section{Discussion}

This study analyzed the histopathological effect of antithrombotic prophylactic-adjusted doses of enoxaparin and rivaroxaban on Achilles tendon healing. The literature includes a few clinical and experimental studies about antithrombotic agents' application and its histological effect on tendon healing. ${ }^{15-17}$ 
Table 1 Histological results of the study groups

\begin{tabular}{|c|c|c|c|}
\hline & Group 1 (sham-control) & Group 2 & Group 3 \\
\hline & No medication & $\begin{array}{l}\text { Group } 2 \text { received } \\
2.03 \mathrm{mg} / \mathrm{kg} \text { rivaroxaban }\end{array}$ & $\begin{array}{l}\text { Group } 3 \text { was given } \\
\text { subcutaneous } 114 \mathrm{IU} \\
\text { AXa nadroparin calcium }\end{array}$ \\
\hline \multirow[t]{8}{*}{ The degree of inflammation $^{a}$} & 1 & 1 & 1 \\
\hline & 2 & 1 & 1 \\
\hline & 3 & 1 & 1 \\
\hline & 2 & 1 & 1 \\
\hline & 1 & 1 & 1 \\
\hline & 1 & 1 & 1 \\
\hline & 2 & 1 & 1 \\
\hline & 1 & 1 & 1 \\
\hline Interpretation of the results & $\begin{array}{l}\text { Higher compared } \\
\text { with group } 2 \text {, group } 3 \\
\left({ }^{\mathrm{b}} p=0.02 \text { and } p=0.02\right)\end{array}$ & $\begin{array}{l}\text { Lower compared } \\
\text { with group } 1 \\
\left({ }^{b} p=0.02\right)\end{array}$ & $\begin{array}{l}\text { Lower compared } \\
\text { with group } 1 \\
\left({ }^{\mathrm{b}} p=0.02\right)\end{array}$ \\
\hline \multirow[t]{8}{*}{ Neovascularization $^{c}$} & 2 & 1 & 1 \\
\hline & 2 & 2 & 1 \\
\hline & 2 & 1 & 2 \\
\hline & 2 & 2 & 2 \\
\hline & 2 & 2 & 2 \\
\hline & 2 & 1 & 2 \\
\hline & 2 & 1 & 1 \\
\hline & 1 & 2 & 2 \\
\hline \multicolumn{4}{|c|}{ Interpretation of the results ${ }^{\mathrm{c}}$-There was no significant difference in the capillary vessels among groups. } \\
\hline \multirow[t]{8}{*}{ Fibroblastic activity $^{\mathrm{a}}$} & 1 & 2 & 1 \\
\hline & 2 & 1 & 1 \\
\hline & 2 & 1 & 2 \\
\hline & 2 & 2 & 2 \\
\hline & 2 & 2 & 1 \\
\hline & 2 & 1 & 1 \\
\hline & 1 & 1 & 1 \\
\hline & 1 & 1 & 1 \\
\hline Interpretation of the results & $\begin{array}{l}\text { Higher in group } 1 \\
\text { compared with groups } 2 \\
\text { and }\left({ }^{b} p=0.01 \text { and }\right. \\
p=0.003 \text {, respectively })\end{array}$ & $\begin{array}{l}\text { Lower in group } 2 \\
\text { compared with } \\
\text { group } 1\left({ }^{b} p=0.01\right)\end{array}$ & $\begin{array}{l}\text { Lower in group } 3 \\
\text { compared with } \\
\text { group } 1\left({ }^{b} p=0.003\right)\end{array}$ \\
\hline \multirow[t]{8}{*}{ Collagen fiber sequencing $^{\mathrm{d}}$} & 1 & 2 & 2 \\
\hline & 1 & 2 & 2 \\
\hline & 1 & 2 & 2 \\
\hline & 1 & 2 & 2 \\
\hline & 1 & 2 & 3 \\
\hline & 1 & 2 & 3 \\
\hline & 2 & 2 & 3 \\
\hline & 2 & 2 & 3 \\
\hline
\end{tabular}


Table 1 (Continued)

\begin{tabular}{|l|l|l|l|}
\hline & Group 1 (sham-control) & Group 2 & Group 3 \\
\cline { 2 - 4 } & No medication & $\begin{array}{l}\text { Group 2 received } \\
2.03 \mathrm{mg} / \mathrm{kg} \text { rivaroxaban }\end{array}$ & $\begin{array}{l}\text { Group } 3 \text { was given } \\
\text { subcutaneous 114 IU } \\
\text { AXa nadroparin calcium }\end{array}$ \\
\hline Interpretation of the results & $\begin{array}{l}\text { Lower in group 1 } \\
\text { compared with group 2, } \\
\text { group 3 ( } \mathrm{b} p=0,04 \text { and } \\
p=0.001, \text { respectively) }\end{array}$ & $\begin{array}{l}\text { Higher in group 2 } \\
\text { compared with } \\
\left.\text { group 1 ( }{ }^{\mathrm{b}} p=0.04\right)\end{array}$ & $\begin{array}{l}\text { Higher in group } 3 \\
\text { compared with } \\
\left.\text { group } 1 \text { ( }{ }^{\mathrm{b}} p=0.001\right)\end{array}$ \\
\hline
\end{tabular}

Note: The healing condition of the tendons was measured histopathologically, by using Curtis and Delee's staging method. ${ }^{21}$

Group 1: No medication; Group 2: rivaroxaban; Group 3: nadroparin calcium.

Data are expressed as median, interquartile range.

a Rated as follows: none (0), mild (1), moderate (2), and pronounced (3).

${ }^{b}$ Kruskal-Wallis $\mathrm{H}$ test.

'Number of capillaries, which were less than five was rated as mild (1), 5 to 10 rated as moderate (2), and greater than 10 as pronounced (3).

${ }^{\mathrm{d} C o l l a g e n ~ f i b e r ~ s e q u e n c i n g ~ w e r e ~ r a t e d ~ a s ~ f o l l o w s: ~ S c a t t e r e d ~(1), ~ s l i g h t l y ~ r e g u l a r ~(2), ~ a n d ~ r e g u l a r ~(3) . ~}$
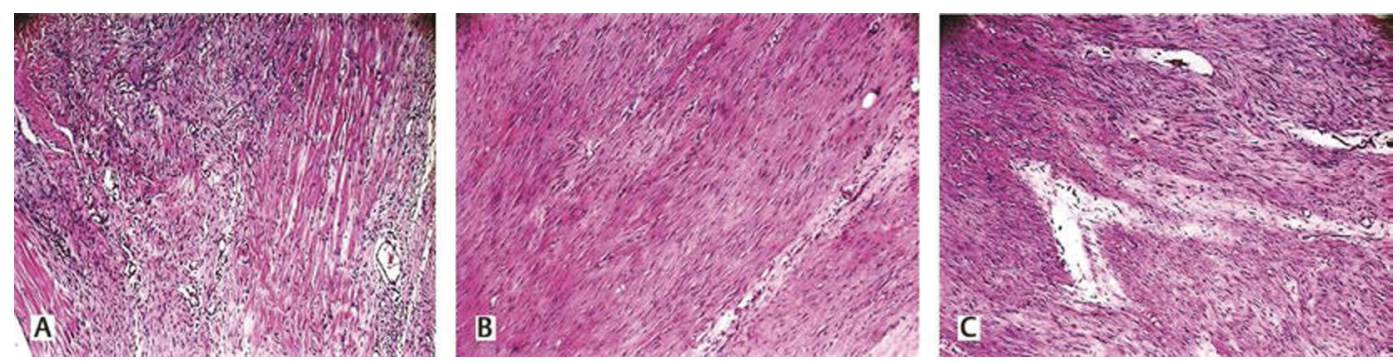

Fig. 2 Tissue samples with hematoxylin and eosin staining $\times 400$ under light microscopy at $\times 10$ magnification. Group 1 received no medication (A); Group 2 received rivaroxaban (B); Group 3 received nadroparin calcium (C).

Table 2 Histological analysis of the number of inflammatory cells, vascular tissues, and fibroblasts between groups

\begin{tabular}{|c|c|c|c|c|c|c|c|}
\hline & \multirow{3}{*}{$\begin{array}{l}\text { Group } 1 \\
\text { Mean } \pm \text { SD } \\
(95 \% \mathrm{Cl})\end{array}$} & \multirow{3}{*}{$\begin{array}{l}\text { Group } 2 \\
\text { Mean } \pm \text { SD } \\
(95 \% \mathrm{Cl})\end{array}$} & \multirow{3}{*}{$\begin{array}{l}\text { Group } 3 \\
\text { Mean } \pm \text { SD } \\
(95 \% \mathrm{Cl})\end{array}$} & \multicolumn{4}{|c|}{ One-way ANOVA } \\
\hline & & & & \multirow[t]{2}{*}{$F$} & \multirow[t]{2}{*}{$p$-Value ${ }^{a}$} & \multicolumn{2}{|c|}{ Tukey's HSD } \\
\hline & & & & & & Group & $p$-Value $^{\mathrm{b}}$ \\
\hline \multirow[t]{3}{*}{ Inflammatory cells } & $9.50 \pm 9.06$ & $2.37 \pm 1.18$ & $5.50 \pm 2.67$ & \multirow[t]{3}{*}{3.35} & \multirow[t]{3}{*}{0.01} & $1-2$ & 0.01 \\
\hline & $(2.38-12.83)$ & $(1.62-3.25)$ & $(3.75-7.12)$ & & & $1-3$ & 0.45 \\
\hline & & & & & & $2-3$ & 0.01 \\
\hline \multirow[t]{3}{*}{ Capillary vessels } & $7.88 \pm 2.84$ & $9.35 \pm 3.24$ & $6.38 \pm 1.93$ & \multirow[t]{3}{*}{2.35} & \multirow[t]{3}{*}{0.11} & $1-2$ & 0.54 \\
\hline & $(6.25-9.83)$ & $(7.51-11.48)$ & $(5.06-7.60)$ & & & $1-3$ & 0.52 \\
\hline & & & & & & $2-3$ & 0.10 \\
\hline \multirow[t]{3}{*}{ Fibroblasts } & $116.32 \pm 24.20$ & $84.61 \pm 21.95$ & $78.47 \pm 12.47$ & \multirow[t]{3}{*}{8.09} & \multirow[t]{3}{*}{0.002} & $1-2$ & 0.01 \\
\hline & $(101.58-133.17)$ & $(70.17-97.38)$ & $(71.10-86.95)$ & & & $1-3$ & 0.003 \\
\hline & & & & & & $2-3$ & 0.81 \\
\hline
\end{tabular}

Note: Group 1: No medication; Group 2: rivaroxaban; Group 3: nadroparin calcium. Data are expressed as mean standard deviation (SD) (95\% confidence interval [CI]).

${ }^{a}$ One-way analysis of variance (one-way ANOVA); significance level set at $<0.05$.

bTukey's honestly significant difference (HSD) test; significance level set at $<0.05$.

Our findings revealed that antithrombotic agent administration with adjusted doses decreased the degree of inflammation and increased regular collagen fiber sequencing in rats after tendon repair. Furthermore, the density of inflammatory cells was lower in rats who received rivaroxaban for 28 days than in rats who received nadroparin calcium for 28 days. However, the density of fibroblasts was higher in rats who received no medication at all, compared with the other groups.

There has been recent evidence that inflammation modulation at the early stages of tendon reparation may lead to improved healing. ${ }^{24}$

However, in our experiment, we performed histopathological examination in the late phase of tendon healing. 
Therefore, the evidence of inflammation and fibroblasts should be interpreted as unregulated inflammation.

As discussed, and revealed in the past literature, controlled inflammation is largely beneficial to tissue recovery, whereas excessive inflammation, or persistence, can be detrimental. ${ }^{25,26}$

Although inflammatory cytokines draw fibroblasts to the repair site, excessive inflammation may lead to poor clinical outcomes. $^{25,26}$

Another question should be asked by readers why an experimental period of 28 days has been chosen. Because, from prior investigations in rats, it is known that the main changes in tendon healing occur within the first 2 weeks; therefore, this study was designed with an observation period of 4 weeks, possibly limiting the significance of the further progression of biomechanical properties. ${ }^{27}$

Another point of view regarding the time interval has been reported by Akamatsu et al. They postulated that a period of 28 days is suggested as a period needed for collagen recovery of the injured tendon. ${ }^{28}$

Tendon healing comprises three main phases. In the past, growth factors and cytokines that have positive effects and that are involved in various stages have been identified in these three main phases. ${ }^{20}$ The positive effects of growth factors have also been demonstrated in animal experiments and aside from these, ${ }^{29,30}$ experimental studies have highlighted that cytokines from autologous conditioned serum and cartilage-derived morphogenetic proteins contribute significantly to tendon healing. ${ }^{31,32}$

In a study on the above-mentioned growth factors and cytokines, a cancer treatment drug named bevacizumab, developed against vascular endothelial growth factor (VEGF), has been reported to improve tendon healing in an experimental study as opposed to the general philosophy. ${ }^{33}$ However, if VEGF is a chemical that contributes to tendon healing, the antibody developed against it would be expected to have an adverse effect.

In another study, Müller et al investigated the effect of a group of growth factors (a validated combination of basic fibroblast growth factor, bone morphogenetic protein-12, and transforming growth factor- $\beta 1$ ) in the presence and absence of the paratenon layer. They stressed that growth factors would only improve tendon healing in the presence of the paratenon layer. ${ }^{11}$

Antithrombotic nadroparin and rivaroxaban are among the main medications we use of antithrombotic prophylaxis of lower extremity trauma or orthopaedic surgery involving the lower extremity. ${ }^{34,35}$ Therefore, these agents' positive or negative contributions to Achilles tendon healing are significant. In a previous study, Virchenko et $\mathrm{al}^{36}$ established an experimental Achille's tendon rupture model in rats and focused on the effect of thrombin on tendon healing.

Thrombin has remarkably similar molecular features as growth factors. The results of this study revealed that thrombin had a positive effect on tendon healing. They hypothesized that $\mathrm{LMWH}$, which inhibits the activity and generation of thrombin, might also inhibit tendon healing. They conducted an experimental study on rats that focused on the dose-dependent effects of LMWH on tendon healing and concluded that LMWH slows tendon repair if given continuously. ${ }^{17}$ However, if injected twice daily, LMWH had no effect on tendon healing, presumably because the antifactor Xa activity between injections returns to normal, allowing sufficient thrombin stimulation for repair.

Following Virchenko et al's study, two other studies focused on the effect of antithrombotics, one of them solely focused on various doses of nadroparin's effect, and the other one focused on nadroparin's and rivaroxaban's effect. ${ }^{15,16}$ Esen et al conducted an experimental study on rats and compared the effects of two different daily doses of LMWH injections (nadroparin calcium) on tendon healing and evaluated the results histologically as well as biomechanically. ${ }^{16}$ All rats underwent full-thickness surgical incisions of the Achilles tendon, followed by primary repair. After the operation, two groups received daily subcutaneous LMWH injections (nadroparin calcium) for 4 weeks at high or low doses (group 1, $6 \mathrm{mg} / \mathrm{kg}, 170 \mathrm{IU}$ AXa; group 2, $3 \mathrm{mg} / \mathrm{kg}, 85 \mathrm{IU}$ AXa), and group 3 remained untreated as the control group. The results showed that group 1, receiving 170 IU AXa daily, had substantially higher overall failure and elongation values than groups 2 and 3. Histologically, both groups 1 and 2 showed superior results when compared with the control group. ${ }^{16}$ These findings also support our theory regarding the positive impact of nadroparin calcium. In addition to this study, we found that rivaroxaban-human dosage 0.33 $\mathrm{mg} / \mathrm{mg} / \mathrm{kg}$ divided by $0.162 \mathrm{~K}_{\mathrm{m}}$ and found animal equivalent dose with a dosage of $2.03 \mathrm{mg} / \mathrm{kg}$ also positively impacted the tendon healing process. Nair and Jacob. ${ }^{18,19}$ wrote a review article that provides basic information about the translation of doses between species and estimation of starting dose for experimental studies, using allometric scaling of US Food and Drug Administration (FDA). The animal equivalent dose can also be calculated based on body surface area by either dividing or multiplying the human dose $\left(\mathrm{mg} / \mathrm{kg}\right.$ ) by the $\mathrm{K}_{\mathrm{m}}$. In our study, we chose to apply $114 \mathrm{IU}$ nadroparin because we adjusted the dose according to the Nair and Jacob ${ }^{18}$ study and FDA scale. ${ }^{19}$ On the other hand, we suggest that the dosage of $170 \mathrm{IU} /$ daily is more than the routine practice. ${ }^{18}$

Eren et al conducted an experimental study on rats and investigated the effects of nadroparin and rivaroxaban on tendon healing. ${ }^{15}$ All rats underwent full-thickness surgical incision of the Achilles tendon followed by primary repair. After the operation, their group 1 received daily subcutaneous nadroparin calcium for 3 weeks at high doses (group 1, $170 \mathrm{IU}$ AXa). Their group 2 received $3 \mathrm{mg} / \mathrm{kg}$ rivaroxaban daily for 21 days through gastric lavage, while group 3 remained untreated, as the control group. This study revealed that nadroparin and rivaroxaban had positive histologic effects on tendon healing in a rat model, although the same outcomes were not obtained in biomechanical assessments. In our study, the effects of the same antithrombotic on tendon healing were investigated; however, we administered the antithrombotic for 1 week longer than Eren et al's study. ${ }^{15}$ One day in a rat's life was approximately equivalent to 34.8 human days; therefore, an additional 1-week more 
follow-up (244 human days [8 months]) would reflect more long-term follow-up data in which it will be more advantageous for research that seeks the effect of some chemicals given systematically on the long-acting tendon healing process. Their study roughly contained similar features as our work, but the following details make a critical difference: first, in our experiment, adjuvants nadroparin and rivaroxaban were administered to the subjects for 28 days rather than 21 days. The difference in administration time makes an important distinction, since as we pointed out, 1 week in the rat subjects' life corresponds to 8 months in human life, which is equivalent to the 8 months postoperative follow-up time. This important difference might make a significant difference in monitoring tendon healing. Another significant distinction is that rivaroxaban and nadroparin were diluted in various proportions: adjusted doses were calculated according to the allometric scale that provides basic information about the translation of doses between species and an estimation of the starting dose for experimental animal studies, which also corresponds to dosage suitable for their daily use. A regular dosage of nadroparin calcium (114 IU) and rivaroxaban $(2.03 \mathrm{mg} / \mathrm{kg})$ was applied in our research and led to a histologically better outcome than the control group.

The strength of our study is the use of adjusted doses of rivaroxaban and nadroparin calcium; however, its limitations should also be highlighted. First, Achilles tendon ruptures in humans usually occur in the final event during the degeneration process. In our study, we performed iatrogenic cuts on healthy rat tendons and repaired them; therefore, the findings should be interpreted with caution. Second, our study had a relatively small sample size; here again, the findings should be interpreted with caution. Finally, the short-term or long-term biomechanical results of these agents on tendon healing were not investigated. One of the weak points of this study is the lack of biomechanical examination.

On the other hand, in this animal experiment, the artificially formed Achilles tendon rupture was stitched with 4-0 (PDS II), suture material and the Kessler suture method were used, so it should not be forgotten that there are two additional factors that may affect the results of the experiment in testing the biomechanical strength of the tendon healing. These are the suture holding capacity of suture material and suture technique.

Therefore, according to us, it might be possible that biomechanical testing in research aimed at testing the effect of some adjuvants on tendon healing would has been biased by suture material and technique.

\section{Conclusion}

Both rivaroxaban and nadroparin calcium in their daily adjusted dosage have a beneficial effect on rats' Achilles tendon healing, and thus, its use as an antithrombotic agent will also contribute positively to the tendon healing process after Achilles tendon repair. Further studies with larger sample sizes are needed to analyze the effects of rivaroxaban and nadroparin calcium on the healing process after Achilles tendon repair.

Conflict of Interest

None declared.

\section{References}

1 Andarawis-Puri N, Flatow EL, Soslowsky LJ. Tendon basic science: development, repair, regeneration, and healing. J Orthop Res 2015;33(06):780-784

2 Lemme NJ, Li NY, DeFroda SF, Kleiner J, Owens BD. Epidemiology of Achilles tendon ruptures in the united states: athletic and nonathletic injuries from 2012 to 2016. Orthop J Sports Med 2018;6(11):2325967118808238

3 Galatz LM, Gerstenfeld L, Heber-Katz E, Rodeo SA. Tendon regeneration and scar formation: the concept of scarless healing. J Orthop Res 2015;33(06):823-831

4 Fell D, Enocson A, Lapidus LJ. Surgical repair of acute Achilles tendon ruptures: a follow-up of 639 consecutive cases. Eur J Orthop Surg Traumatol 2020;30(05):895-899

5 Hsu AR, Jones CP, Cohen BE, Davis WH, Ellington JK, Anderson RB. Clinical outcomes and complications of percutaneous Achilles repair system versus open technique for acute Achilles tendon ruptures. Foot Ankle Int 2015;36(11):1279-1286

6 Taşatan E, Emre TY, Demircioğlu DT, Demiralp B, Kırdemir V. Long-term results of mini-open repair technique in the treatment of acute Achilles tendon rupture: a prospective study. J Foot Ankle Surg 2016;55(05):971-975

7 Liles J, Adams SB Jr. Management of complications of Achilles tendon surgery. Foot Ankle Clin 2019;24(03):447-457

8 Meulenkamp B, Stacey D, Fergusson D, Hutton B, Mlis RS, Graham ID. Protocol for treatment of Achilles tendon ruptures; a systematic review with network meta-analysis. Syst Rev 2018;7(01):247

9 Park SH, Lee HS, Young KW, Seo SG. Treatment of acute Achilles tendon rupture. Clin Orthop Surg 2020;12(01):1-8

10 Gissi C, Radeghieri A, Antonetti Lamorgese Passeri Cet al.Extracellular vesicles from rat-bone-marrow mesenchymal stromal/ stem cells improve tendon repair in rat Achilles tendon injury model in dose-dependent manner: a pilot study. PLoS One 2020; 15(03):0229914

11 Müller SA, Quirk NP, Müller-Lebschi JAet al.Response of the injured tendon to growth factors in the presence or absence of the paratenon. Am J Sports Med 2019;47(02):462-467

12 Slomski A. Platelet-rich plasma doesn't facilitate Achilles tendon healing. JAMA 2020;323(08):701

13 Alviti F, Gurzì M, Santilli Vet al.Achilles tendon open surgical treatment with platelet-rich fibrin matrix augmentation: biomechanical evaluation. J Foot Ankle Surg 2017;56(03):581-585

14 Nilsson-Helander K, Thurin A, Karlsson J, Eriksson BI. High incidence of deep venous thrombosis after Achilles tendon rupture: a prospective study. Knee Surg Sports Traumatol Arthrosc 2009;17 (10):1234-1238

15 Eren Y, Adanır O, Dinçel YM, Genç E, Arslan YZ, Çağlar A. Effects of low molecular weight heparin and rivaroxaban on rat Achilles tendon healing. Eklem Hastalik Cerrahisi 2018;29(01):13-19

16 Esen E, Cila E, Ozoğul Cet al.[The effect of low-molecular-weight heparin on rat tendon healing]. Acta Orthop Traumatol Turc 2009; 43(01):54-61

17 Virchenko O, Aspenberg P, Lindahl TL. Low molecular weight heparin impairs tendon repair. J Bone Joint Surg $\mathrm{Br}$ 2008;90 (03):388-392

18 Nair AB, Jacob S. A simple practice guide for dose conversion between animals and human. J Basic Clin Pharm 2016;7(02): 27-31

19 Food and Drug Administration. Guidance for Industry Estimating the Maximum Safe Starting Dose in Initial Clinical Trials for 
Therapeutics in Adult Healthy Volunteers. Rockville, MD 20857: National Press Office July 10, 2005. Accessed April 07, 2021 at: https://www.fda.gov/media/72309/download

20 Oliva F, Via AG, Maffulli N. Role of growth factors in rotator cuff healing. Sports Med Arthrosc Rev 2011;19(03):218-226

21 Murrell GA, Lilly EG III, Goldner RD, Seaber AV, Best TM. Effects of immobilization on Achilles tendon healing in a rat model.J Orthop Res 1994;12(04):582-591

22 Eliasson P, Andersson T, Aspenberg P. Achilles tendon healing in rats is improved by intermittent mechanical loading during the inflammatory phase. J Orthop Res 2012;30(02):274-279

23 Curtis RJ, Delee JC, Drez DJ Jr. Reconstruction of the anterior cruciate ligament with freeze dried fascia lata allografts in dogs. A preliminary report. Am J Sports Med 1985;13(06):408-414

24 Hays PL, Kawamura S, Deng XHet al.The role of macrophages in early healing of a tendon graft in a bone tunnel. J Bone Joint Surg Am 2008;90(03):565-579

25 Sugg KB, Lubardic J, Gumucio JP, Mendias CL. Changes in macrophage phenotype and induction of epithelial-to-mesenchymal transition genes following acute Achilles tenotomy and repair. J Orthop Res 2014;32(07):944-951

26 Lichtnekert J, Kawakami T, Parks WC, Duffield JS. Changes in macrophage phenotype as the immune response evolves. Curr Opin Pharmacol 2013;13(04):555-564

27 Müller SA, Dürselen L, Heisterbach P, Evans C, Majewski M. Effect of a simple collagen type I sponge for Achilles tendon repair in a rat model. Am J Sports Med 2016;44(08):1998-2004
28 Akamatsu FE, Saleh SO, Teodoro WRet al.Experimental model of Achilles tendon injury in rats. Acta Cir Bras 2014;29(07):417-422

29 Hou Y, Mao Z, Wei Xet al.The roles of TGF-beta1 gene transfer on collagen formation during Achilles tendon healing. Biochem Biophys Res Commun 2009;383(02):235-239

30 Cui J, Chen Z, Wu W. Expression of TGF- $\beta 1$ and VEGF in patients with Achilles tendon rupture and the clinical efficacy. Exp Ther Med 2019;18(05):3502-3508

31 Majewski M, Ochsner PE, Liu F, Flückiger R, Evans CH. Accelerated healing of the rat Achilles tendon in response to autologous conditioned serum. Am J Sports Med 2009;37(11):2117-2125

32 Forslund C, Aspenberg P. Improved healing of transected rabbit Achilles tendon after a single injection of cartilage-derived morphogenetic protein-2. Am J Sports Med 2003;31(04):555-559

33 Tempfer $\mathrm{H}$, Kaser-Eichberger A, Lehner Cet al.Bevacizumab improves Achilles tendon repair in a rat model. Cell Physiol Biochem 2018;46(03):1148-1158

34 Flevas DA, Megaloikonomos PD, Dimopoulos L, Mitsiokapa E, Koulouvaris P, Mavrogenis AF. Thromboembolism prophylaxis in orthopaedics: an update. EFORT Open Rev 2018;3(04):136-148

35 David AF. Deep Venous Thrombosis Prophylaxis in Orthopedic Surgery: Background, Mechanical Methods, pharmacologic Methods. Accessed April 07, 2021 at: https://emedicine. medscape.com/article/1268573-overview

36 Virchenko O, Grenegård M, Aspenberg P. Independent and additive stimulation of tendon repair by thrombin and platelets. Acta Orthop 2006;77(06):960-966 